\title{
Low genetic variability of the edible dormouse (Glis glis) in Stolowe Mountains National Park (Poland) —preliminary results
}

\author{
Magdalena Moska $^{1}$ - Jadwiga Jakubiec ${ }^{2}$ Heliodor Wierzbicki ${ }^{1}$ Tomasz Strzala ${ }^{1}$. \\ Katarzyna Kozyra ${ }^{1}$
}

Received: 29 January 2016 / Accepted: 17 June 2016 / Published online: 25 June 2016

(C) The Author(s) 2016. This article is published with open access at Springerlink.com

\begin{abstract}
The edible dormouse (Glis glis) from Stolowe Mountains National Park (south-western Poland) was studied to reveal the genetic diversity of dormice living in the Polish Sudetes. Material (hair with roots) collected from 39 individuals (adults and juveniles) was used for genetic testing to perform population analyses. Molecular study involved two types of markers: nuclear DNA (11 microsatellite sequences) and mitochondrial DNA (fragment of cytochrome $b$ of approximately $700 \mathrm{bp}$ in length). Low genetic variability of the studied population was found. Two of the microsatellite loci proved to be completely monomorphic, whereas the degree of polymorphism of other microsatellites was also unexpectedly low. Only two haplotypes were found among all 39 individuals. Low genetic diversity of dormice from the Polish Sudetes, determined by genotyping of nuclear molecular markers, may be the consequence of fragmentation of this species' population. Dormouse sites in Poland have been declining for decades due to deforestation and fragmentation of old forests. Therefore, dormice live in small populations in isolated habitats with increasing levels of homozygosity. Other possible causes of low genetic variability of G. glis are discussed as well.
\end{abstract}

Keywords Genetic diversity $\cdot$ Gliridae $\cdot$ Microsatellite Deforestation

Communicated by: Magdalena Niedziałkowska

Magdalena Moska

magdalena.moska@up.wroc.pl

1 Department of Genetics, Wroclaw University of Environmental and Life Sciences, Kozuchowska 7, 51-631 Wroclaw, Poland

2 The Stolowe Mountains National Park, Kudowa-Zdrój, Poland

\section{Introduction}

The edible dormouse Glis glis, an arboreal rodent of the family Gliridae, is a widespread mammal throughout most of Europe. In Poland, as a rare animal threatened by extinction, G. glis is a protected species. It is generally more abundant in the southern and eastern parts of the country, whereas dormouse sites in the remaining regions, particularly in central and northern Poland, are sparse (Pucek and Jurczyszyn 2001; Jurczyszyn 2015). In many sites, environmentally isolated populations with no gene flow between one population to another are found (Jurczyszyn 1996; Bartmańska et al. 2010; Trzop and Moska 2013). Isolation leading, among others, to a decrease in heterozygosity may result in their extinction. According to the historic data, this mammal disappeared during a period of more than a hundred years from a number of Polish sites, including almost all located in north-western Poland (Pucek 1983; Jurczyszyn and Wołk 1998; Jurczyszyn 2001). Improper forest management, which has been carried out in the country for decades, is considered a main cause of this state. It is well known that tree-dependent species that rarely venture to the ground are highly sensitive to forest fragmentation. Low genetic variability of the edible dormouse resulting from habitat fragmentation was found by Fietz et al. (2014). Also, Taylor et al. (2011) who studied the squirrel glider (Petaurus norfolcensis), a nocturnal arboreal mammal living in Australia, reported its low genetic variability caused by habitat fragmentation and destruction.

Scarce genetic studies of G. glis, based on an analysis of nuclear and mitochondrial DNA, indicate very low genetic diversity in this species (Dabert et al. 2009; Segelbacher et al. 2010; Hürner et al. 2010; Lo Brutto et al. 2011; Helvaci et al. 2012; Castiglia et al. 2012; Herdegen et al. 2016). Segelbacher et al. (2010) reported low genetic variation in one of the German populations of the edible dormouse. The 
authors of the study investigated genetic variability in a sample of 77 dormice using 10 microsatellite loci. Comparable results were obtained by Dabert et al. (2009) who revealed comparatively low genetic variation in dormice populations in Spain, Belgium, and Poland.

In general, low genetic variability of the European dormice is also confirmed when using mitochondrial DNA (mtDNA). The results of the studies taking into account almost 200 dormice sampled across western, middle, and southern Europe revealed that the main part of Europe harbors a single mtDNA cytochrome $b$ haplogroup (European haplogroup). Only Italy, Sicily, Macedonia, and Alonissos (Sporades archipelago, Greece) are inhabited by G. glis belonging to other haplogroups (South Italian group, Sicilian group) and atypical haplotypes (Macedonia, Alonissos) (Hürner et al. 2010; Lo Brutto et al. 2011; Castiglia et al. 2012). The latest studies carried out in Turkey and Poland confirmed that all analyzed dormice of these studies (cytochrome $b$ was investigated) belonged to the European haplogroup (Helvaci et al. 2012; Herdegen et al. 2016). The authors of all these studies concluded that their genetic analyses evidenced an amazing homogeneity throughout the Eurasian range of G. glis.

Therefore, besides being extremely important for dormouse habitat conservation activities, there is a need to elucidate the genetic diversity reflecting the history of the species and predicting its future. For this reason, the aim of the study was to reveal the genetic diversity of dormice living in the Stolowe Mountains National Park, a small area in the Sudetes (south-western Poland). Knowledge on genetic structure of the studied population would be useful when selecting individuals for the dormouse reintroduction program carried out in Poland.

\section{Material and methods}

The study was conducted in 2013 (from the beginning of August to the end of October) in the Stolowe Mountains National Park (SMNP). In total, 39 individuals (18 adults and 21 juveniles) captured in bird nest boxes set up in three study sites (Permission No. DOPpn-4102/165/10997/11/RS) (Fig. 1) were investigated. The distribution of captured dormice among the study sites was as follows: site I -5 individuals, site II-8 individuals, site III-26 individuals. Each individual was marked with a unique ear tattoo. The capture procedure used in the study implies that we cannot exclude the possibility that closely related individuals were also sampled.

The site was located in a mixed mountain fresh forest, with a full canopy closure. Age of trees ranged from 35 to 130 years, and the occurring species were beech (Fagus sylvatica), spruce (Picea abies), larch (Larix polonica), birch (Betula pendula), sycamore (Acer pseudoplatanus), and ash
(Fraxinus excelsior). Sites II and III were covered by fresh mountain forest (fertile Sudeten beech forest). Full canopy closure was present in the site II; age of the trees ranged from 15 to 150 years, and the following species were occurring: beech, birch, sycamore, maple (A. platanoides), mountain ash (Sorbus aucuparia), small-leaved lime (Tilia cordata), white willow (Salix alba), wild cherry (Prunus avium), larch, scots pine (Pinus sylvestris), pedunculate oak (Quercus robur). Canopy closure of site III was uneven; age of the trees ranged from 25 to 200 years, and the species composition was as follows: beech, spruce, sycamore, ash, aspen (Populus tremula), scots pine, larch, silver fir (Abies alba), gray alder (Alnus incana), small-leaved lime, pedunculate oak, wild cherry, horse-chestnut (Aesculus hippocastanum). Straightline distance between the sites was as follows: I-III, ca. $2.5 \mathrm{~km}, \mathrm{I}-\mathrm{II}$, ca. $1.8 \mathrm{~km}, \mathrm{II}-\mathrm{III}$, ca. $700 \mathrm{~m}$. The study sites were connected by forest.

DNA was isolated from hair using Sherlock AX Kit. Eleven polymorphic autosomal microsatellite loci known in G. glis served for the analysis of nuclear DNA (Hürner et al. 2009; Dabert et al. 2013). Based on size limitations and amplification specificity, we distributed the 10 microsatellites into three sets: (1) $G g 3, G g 9, G g 13$, (2) Gg8, Gg12, Gg14, (3) 23pilch, 24pilch, 30pilch, 36pilch. Only 7pilch was amplified separately. Amplification of nuclear DNA fragments was carried out using Qiagen Multiplex PCR Kit and its conditions for each locus were set according to Hürner et al. (2009) and Dabert et al. (2013). In order to improve the estimation of the amplification product size, one primer of each pair was labeled with a fluorescent dye (FAM, JOE or TAMRA) on the 5 '-end, allowing analysis with the use of an ABI 3100 Avant automated sequencer (Applied Biosystems). The amplified alleles were scored in GeneMapper 4 (Applied Biosystems).

The analysis of mtDNA was based on a fragment of cytochrome $b$, of approximately $700 \mathrm{bp}$ in length. The selected fragment was amplified using the cytGlis 1 primer pair, and the PCR reaction conditions were consistent with the literature data (Michaux et al. 2003; Hürner et al. 2010). The resulting products were sequenced and used for analysis of the cytochrome $b$ haplotypes.

Deviations from Hardy-Weinberg equilibrium (HWE), $F_{\mathrm{IS}}$, as well as the number of alleles at a given locus were estimated with Genepop 4.2.1 software (Rousset 2008). False discovery rate (FDR) was used as a correction for multiple comparison analysis (Benjamini and Hochberg 1995). Expected and observed heterozygosity for individual loci were calculated using Arlequin 3.5.1.3 software (Excoffier and Lischer 2010). Furthermore, to search for large allele dropout and microsatellite scoring errors, we used three different computer programs: Microchecker 2.2.3 (Van Oosterhout et al. 2004), MLNullFreq (Kalinowski and Taper 2006), and Genepop 4.2.1 (Rousset 2008). Population genetic structure was analyzed with Bayesian approach implemented in Structure v. 2.3.4 


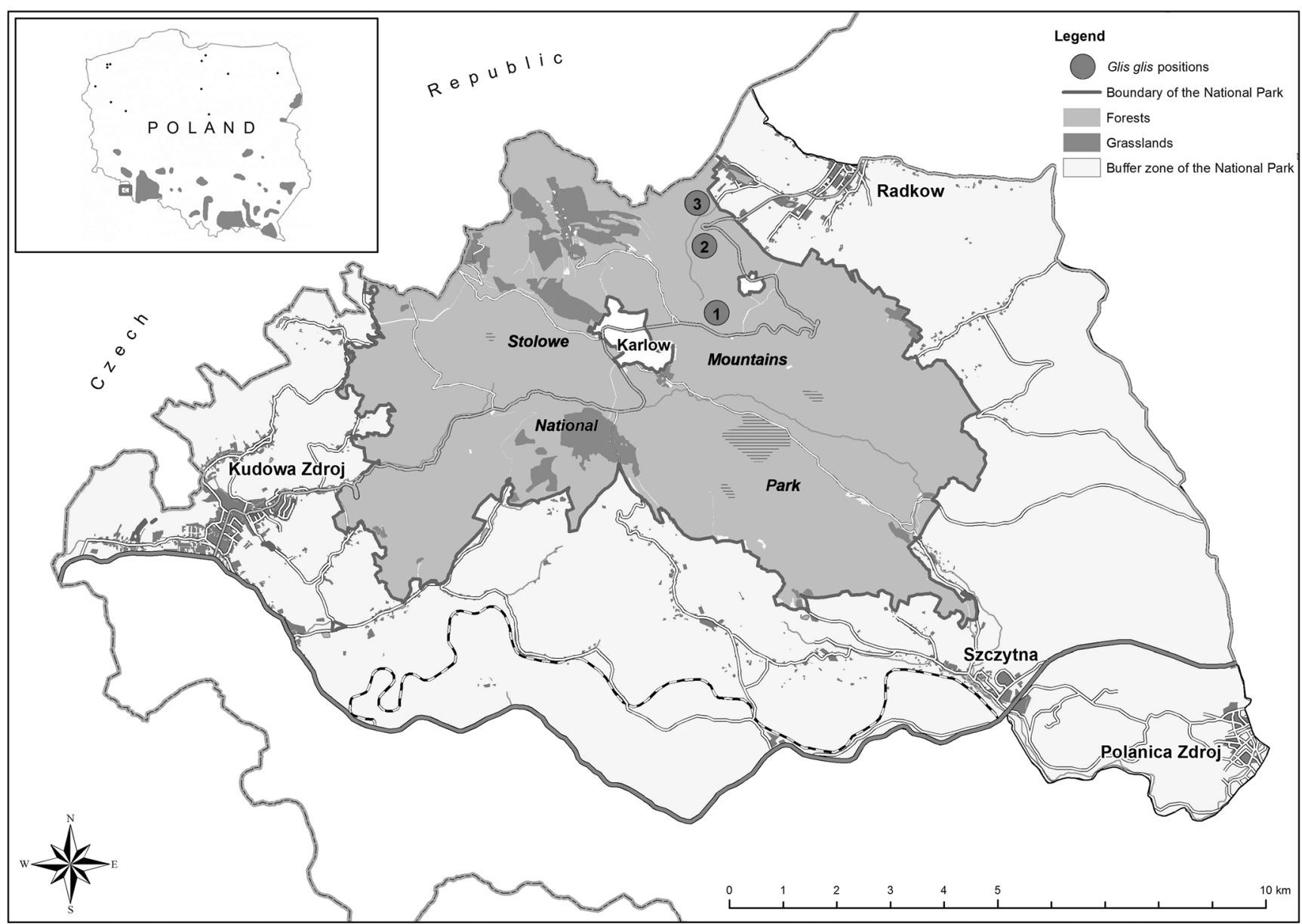

Fig. 1 Map of the Stolowe Mountains National Park with indicated (circles) studied areas and the distribution of Glis glis in Poland (Jurczyszyn 2015)

(Pritchard et al. 2000; Falush et al. 2003; Hubisz et al. 2009) without prior information regarding their sampling localities (i.e., USEPOPINFO was not specified). We used correlated allele frequencies with an admixture model, varying $K$ from 1 to 5 . Ten replicates for each $K$ with 200,000 burn-ins and 500,000 replicates were used. Delta $K$ method (Evanno et al. $2005)$ combined with standard prediction of $K$ based on plotted mean ln probability of $K(L(K))$ was applied to analyze Structure results. Both plots (Delta $K$ and $L(K)$ ) were calculated using Structure Harvester (Earl and VonHoldt 2012). Finally, to search for recent population decreases, we used Bottleneck 1.2.02 (Piry et al. 1999).

Phylogenetic analyses were performed using a data set formed from 22 aligned sequences (two from this study and 20 retrieved from Genbank (accession numbers are presented on the tree)) of mitochondrial cytochrome $b$ of the edible dormouse (713 bp in total). The data were analyzed with maximum likelihood (ML) and Bayesian approach (BA) as partitioned into three codon positions. We used Garli 2.01 (Zwickl 2006) (ML) and MrBayes 3.2 (Ronquist et al. 2012) (BA) with models F81 + I, GTR, and K80 for the first, second, and third codon position, respectively, as suggested by jModelTest 2.1.4 (Guindon and Gascuel 2003; Darriba et al.
2012). The conditions were $15,000,000$ MCMC repetitions with $25 \%$ burn-in for MrBayes and 20 search replicates for the best tree topology with 1000 bootstrap replicates for Garli (best tree among 20 search replicates was used as a starting tree in bootstrap analysis). Analyses in MrBayes were completed when average standard deviation of split frequencies was stabilized at a level significantly below 0.01 .

\section{Results and discussion}

Structure results clearly indicated one genetic cluster as the most probable number of genetically distinct populations. The highest $L(K)$ value as well as lowest standard deviation was found for $K=1$. Delta $K$ presented the highest peak for $K=2$, but with this method, it was impossible to indicate $K=1$ as there was no likelihood value for $K=0$. As Structure analysis returned no genetic substructure, all further genetic estimates were computed treating all individuals as one population.

Of the 11 analyzed loci, two proved to be monomorphic in all animals tested. The remaining nine displayed a very low level of polymorphism. In total, 26 alleles were found at 11 autosomal microsatellite loci. The most variable locus 
(30pilch) had only five alleles (Table 1). The observed heterozygosity $\left(H_{\mathrm{O}}\right)$ per locus ranged from 0.03 to 0.71 and averaged 0.26 for all loci, whereas expected heterozygosity $\left(H_{\mathrm{E}}\right)$ ranged from 0.03 to 0.73 with an average value of 0.26 (Table 1). Estimates delivered by Microchecker and MLNullFreq indicated no large allele dropout or microsatellite scoring errors among all analyzed loci (Microchecker estimated NAF $=0.00$ for all analyzed loci, while ML-NullFreq estimated NAF $=0.00$ for all but one locus $-G g 3, \mathrm{NAF}=0.25$ ) and all loci were in HWE after FDR correction. The third software, Genepop, provided partly different results, detecting null alleles at five out of the nine loci examined (NAF at four loci- $G g 3, G g 8, G g 9$, and $G g 13$ was higher than 0.20 , whereas NAF at locus 30pilch reached acceptable level of 0.12). We found no evidence for a recent bottleneck as allele frequency distribution estimated with Bottleneck 1.2.02 (Piry et al. 1999) presented an approximately L-shaped form as expected under mutation-drift equilibrium and the Wilcoxon test results under S.M.M model were as follows: (i) one tail for $\mathrm{H}$ deficiency $p$ value $=0.10156$; (ii) one tail for $\mathrm{H}$ excess $p$ value $=0.91797$; (iii) two tails for $\mathrm{H}$ excess or deficiency $p$ value $=0.20313$.

Only two haplotypes were found among all 39 individuals analyzed in the present study (GenBank accession numbers KM061382, KM061383). Both Polish haplotypes revealed in this study were located in the European haplogroup (EUH), together with cytb haplotypes from France, UK, Spain, Italy, and Germany (BA-0.98/ML-0.84) (Fig. 2).

Our results demonstrated very low genetic variability of the studied population. The degree of polymorphism of nine microsatellite markers in our study was very low (on average, 2.7 alleles/locus). Regarding the number of alleles at a given locus, 36pilch marker deserves special attention in our study. We detected only two different alleles at this locus, whereas the literature data indicate that this is one of the most polymorphic microsatellite markers in the edible dormouse. In

Table 1 Basic parameters of genetic variability estimated for studied Glis glis

\begin{tabular}{llllll}
\hline Locus & $n_{\mathrm{a}}$ & $H_{\mathrm{E}}$ & $H_{\mathrm{O}}$ & $F_{\mathrm{IS}}$ & HWE $p$ value \\
\hline $\mathrm{Gg} 3$ & 2 & 0.274 & 0.160 & 0.422 & 0.083 \\
$\mathrm{Gg} 8$ & 2 & 0.083 & 0.086 & -0.030 & 1.000 \\
$\mathrm{Gg} 9$ & 3 & 0.321 & 0.316 & 0.018 & 0.323 \\
Gg13 & 2 & 0.507 & 0.556 & -0.099 & 0.707 \\
Gg14 & 2 & 0.055 & 0.056 & -0.014 & 1.000 \\
7 pilch & 3 & 0.092 & 0.094 & -0.022 & 1.000 \\
24 pilch & 3 & 0.300 & 0.342 & -0.143 & 1.000 \\
30 pilch & 5 & 0.730 & 0.711 & 0.027 & 0.157 \\
36 pilch & 2 & 0.026 & 0.026 & 0.000 & - \\
Average & 2.667 & 0.265 & 0.261 & 0.019 & - \\
\hline
\end{tabular}

$n_{a}$ number of alleles, $H_{E}$ expected heterozygosity, $H o$ observed heterozygosity, $F_{I S}$ inbreeding coefficient. dormice from Croatia $(n=47)$ and from Poland $(n=$ ca. 370 individuals), Dabert et al. (2013) found at this locus 9 and 12 alleles, respectively.

Literature data indicate that the basic genetic parameters of the European dormouse population confirm its very low level of diversity. Low average values of $H_{\mathrm{O}}$ and $H_{\mathrm{E}}(0.45$ and 0.48 , respectively) were observed in the German population (Segelbacher et al. 2010). The observed and expected heterozygosity obtained by genetic analyses carried out in Spain was at a similar level (0.47 and 0.53 , respectively) (Hürner et al. 2009). These values in the population of the Stolowe Mountains studied by us were almost two times lower, reaching the value of 0.26 for both types of heterozygosity. Our results are closest to the outcomes obtained in Belgium, where genetic diversity based on six microsatellite loci in 36 dormice reached the level of 0.25 and 0.29 for $H_{\mathrm{O}}$ and $H_{\mathrm{E}}$, respectively (Hürner et al. 2009).

We have excluded a few important causes which could have led to low genetic variability of the studied population. First, the population was in HWE and was not inbred. In general, the majority of European populations of G. glis show no deviation from HWE (Hürner et al. 2009; Segelbacher et al. 2010; Fietz et al. 2014). Second, although we found no evidence for a recent bottleneck as a reason for genetic homogeneity of the studied population, Fietz et al. (2014) speculate that low genetic variability of G. glis in Central Europe could be a result of a combination of several bottlenecks during the glacial periods and invasion of only a few individuals that had colonized Central Europe after the last ice age. Third, NAFs estimated using Microchecker and ML-NullFreq indicated no large allele dropout at the examined loci.

Low level of genetic diversity of European population of G. glis can result from biological characteristics of this species: (1) Edible dormice are extreme habitat specialists, preferring a given type of habitat (deciduous and mixed forests consisting of European beeches and oaks) (Pucek and Jurczyszyn 2001). As a result of habitat destruction and fragmentation isolated, genetically homogeneous populations have been formed. Fietz et al. (2014) found that in Germany, dormice inhabiting forest fragments were isolated from each other and their genetic population structure was more unstable over the study period that in the large, continuous forest. Also, Herdegen et al (2016) who studied G. glis in Poland reported that populations from the most fragmented region of Poland were characterized by extremely limited gene flow and low genetic diversity compared to less fragmented populations. However, according to Amos and Balmford (2001), the current fragmentation is not immediately predictive of genetic diversity, most likely because there has been too little time for genetic drift to have an effect. Thus, it cannot be unequivocally stated that recent fragmentation of habitats would have affected genetic variability of dormice; (2) this species has low dispersal abilities. Its mode of 


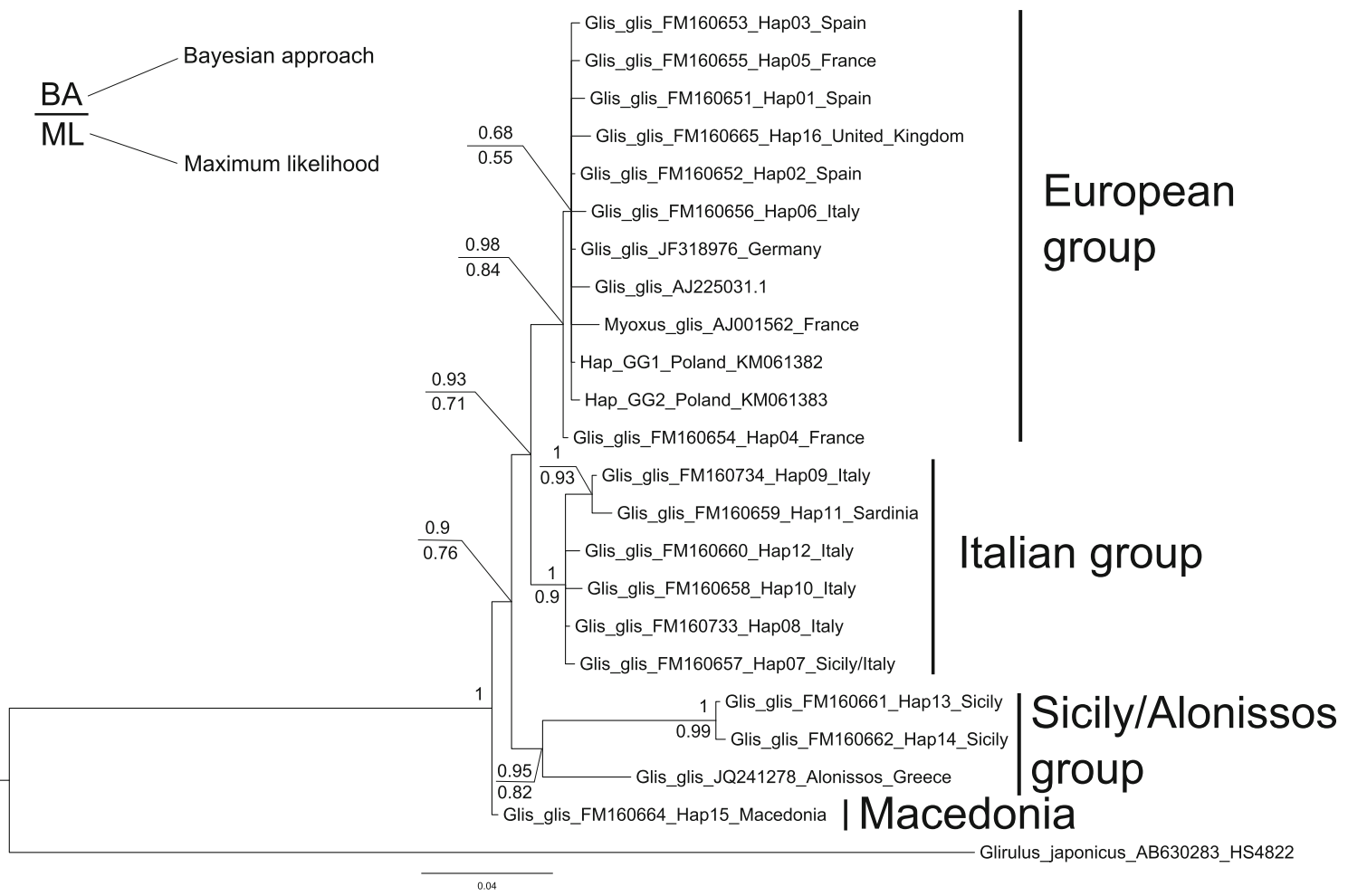

Fig. 2 Phylogenetic tree of 22 aligned mitochondrial cytochrome $b$ edible dormouse sequences. Bayesian posterior probabilities $(B A)$ of nodes are shown above and bootstrap values from maximum likelihood analyses $(M L)$ below

movement that involves jumping from tree to tree means that gaps in tree cover greater than its jumping distance limit its ability to move between habitat patches when foraging or dispersing (Taylor et al. 2011). This in turn drastically reduces gene flow between neighboring but isolated populations, increasing the chances of the next generations being inbred; (3) the reproduction of G. glis is synchronized with the presence or absence of beechnuts and/or acorns. In years with a lack of seeding, beech trees dormice typically stay sexually inactive. In several free-living dormouse populations, dramatically reduced or even absent reproduction under these conditions was observed (Bieber 1998; Pilastro et al 2003; Fietz et al. 2005). A proper age and genetic structure of a population requires, among others, regular breeding. Disruption of this vital process may temporarily caused lower genetic variability and increased inbreeding; (4) finally, one should not exclude the hypothesis that low genetic variability is typical for G. glis and, like in some felines (e.g. Lynx pardinus), has been lasting for a very long time (Rodriguez et al. 2011). This hypothesis should be verified by comparing fossil-DNA of European dormice.

In addition, in many cases, historical reasons are responsible for the very low genetic diversity of a studied species. The Stolowe Mountains, part of the Sudetes, were colonized by humans and partly deforested early in history. The reason for this was the demand for timber and the building of new settlements. Deforestation of this area intensified during the seventeenth and eighteenth centuries, taking place mainly in the lower wooded sections covered by deciduous forest (Staffa 1992). Intensive forest management preferring artificially introduced spruce led to deciduous forest fragmentation and substantial reduction of forested areas. At present, 40-80year-old spruce forests predominant much of the Stolowe Mountains (Mikusek 2010). The anthropogenic transformation of Sudetian forests has had a negative effect on arboreal mammals. The way forest management is carried out today (e.g. removal of dead trees with a hollow trunk, new forest roads and hiking trails, timber harvesting, and transport) brings some other threats for G. glis. The substantial metamorphosis the Stolowe Mountains' forests have gone through over the last centuries is likely to be one of the main causes of low genetic diversity in the studied species. Deforestation and fragmentation of edible dormouse habitat has hindered or even prevented contact between neighboring populations. This may be the reason for the low genetic variability of the dormouse population from the Stolowe Mountains. At present, no study on gene flow among the Sudetian populations of G. glis has been carried out. However, it is known that in the neighboring Bystrzyckie Mountains, several dormouse populations have been found (Bartmańska et al. 2010). Consequently, this type of genetic analysis could be done there.

Apart from nuclear markers, we have used a fragment of mtDNA cytochrome $b$ in genetic analyses. The phylogenetic 
tree presented in this study revealed three main lineages as it was previously shown by Hürner et al. (2010) and Castiglia et al. (2012). Nevertheless, the topology of our tree was slightly different when compared to previous studies (Hürner et al. 2010; Castiglia et al. 2012). European and Italian haplogroups were closest to each other in the current study. The study by Castiglia et al. (2012) reported that the Macedonian haplotype was the closest to the European, whereas Hürner et al. (2010) claimed that the same Macedonian haplotype was closest to the Italian haplogroup. However, those relationships are not well supported in both of these papers. In our study, the haplotype from Macedonia is basal to all other haplotypes and this result is highly supported (BA-1). Location of Alonissos haplotype is another topological difference between our results and the analysis by Castiglia et al. (2012). The study by Castiglia et al. (2012) found that this haplotype did not cluster with any other haplotype and probably belonged to a new mitochondrial lineage. Our results did not support this conclusion. We have demonstrated that the haplotype from Alonissos island clustered with two haplotypes from Sicily (BA-0.95/ML-0.82). Variations in the tree topology may be due to a different methodological approach in tree construction, as we partitioned our data into three codon positions. Separate substitution models for subsets created from data with different evolutionary rates usually produce a better phylogeny, as the model is better fitted and systematic error is reduced (Lanfear et al. 2012).

Although the results of our study on the genetic diversity of the Stolowe Mountains National Park dormice are of a preliminary nature and presented estimates indicating genetic homogeneity of the studied population may be slightly overestimated, they are important for another reason. The dormouse reintroduction program, planned for many years, was started in Poland in 1997 (Jurczyszyn 2001). It concerns the restoration of edible dormice to their historical sites in northwestern Poland. While reintroductions carried out so far have been successful, they point out the need for extending research on the Polish dormouse population with genetic testing. It would solve many dilemmas that mammalogists working on the reintroductions have to face (e.g., selection of individuals for reintroductions with an appropriate genetic profile, and avoiding mating of related individuals).

Acknowledgments We are very grateful to Anna Jonkisz from the Institute of Molecular Techniques (the Wroclaw Medical University, Poland) for laboratory help.

The study was financially supported by the Polish Forest Fund.

Open Access This article is distributed under the terms of the Creative Commons Attribution 4.0 International License (http:// creativecommons.org/licenses/by/4.0/), which permits unrestricted use, distribution, and reproduction in any medium, provided you give appropriate credit to the original author(s) and the source, provide a link to the Creative Commons license, and indicate if changes were made.

\section{References}

Amos W, Balmford A (2001) When does conservation genetics matter? Heredity 87:257-265

Bartmańska J, Moska M, Gottfried T (2010) Recent range and distribution of dormice (Gliridae, Mammalia) in the Sudetes (Poland). Acta Zool Cracov 53:65-78

Benjamini Y, Hochberg Y (1995) Controlling the false discovery rate: a practical and powerful approach to multiple testing. J R Stat Soc B 57:289-300

Bieber C (1998) Population dynamics, sexual activity, and reproduction failure in the fat dormouse (Myoxus glis). J Zool (Lond) 244:223-229

Castiglia R, Annesi F, Cattaneo C, Grano M, Milana G, Amori G (2012) A new mitochondrial lineage in the edible dormouse, Glis glis (Rodentia: Gliridae), from Alonissos island (Sporades Archipelago, Greece). Folia Zool 61:177-180

Dabert M, Jarmołowski A, Jurczyszyn M (2009) New polymorphic microsatellite loci developed and characterized from edible dormouse (Glis glis). Conserv Genet 10:2029-2031

Dabert M, Sobczyńska U, Abramowski D, Konjević D, Margaletić J, Jurczyszyn M (2013) New fourteen highly polymorphic STR markers developed and characterized from edible dormouse (Glis glis). Conserv Genet Resour 5:429-431

Darriba D, Taboada GL, Doallo R, Posada D (2012) jModelTest 2: more models, new heuristics and parallel computing. Nat Methods 9:772-772

Earl DA, VonHoldt BM (2012) Structure harvester: a website and program for visualizing structure output and implementing the Evanno method. Conserv Genet Resour 4:359-361

Evanno G, Regnaut S, Goudet J (2005) Detecting the number of clusters of individuals using the software structure: a simulation study. Mol Ecol 14:2611-2620

Excoffier L, Lischer HEL (2010) Arlequin suite ver 3.5: a new series of programs to perform population genetics analyses under Linux and Windows. Mol Ecol Resour 10:564-567

Falush D, Stephens M, Pritchard JK (2003) Inference of population structure using multilocus genotype data: linked loci and correlated allele frequencies. Genetics 164:1567-1587

Fietz J, Pflug M, Schlund W, Tataruch F (2005) Influences of the feeding ecology on body mass and possible implications for reproduction in the edible dormouse (Glis glis). J Comp Physiol B 175:45-55

Fietz J, Tomiuk J, Loeschcke V, Weis-Dootz T, Segelbacher G (2014) Genetic consequences of forest fragmentation for a highly specialized arboreal mammal - the edible dormouse. PLoS ONE 9(2): e88092

Guindon S, Gascuel O (2003) A simple, fast, and accurate algorithm to estimate large phylogenies by maximum likelihood. Syst Biol 52: 696-704

Helvaci Z, Renaud S, Ledevin R, Adriaens D, Michaux J, Colak R, Kankilic T, Kandemir I, Yiğit N, Colak E (2012) Morphometric and genetic structure of the edible dormouse (Glis glis): a consequence of forest fragmentation in Turkey. Biol J Linn Soc 107:611-623

Herdegen M, Radwan J, Sobczynska U, Dabert M, Konjević D, Schlichter J, Jurczyszyn M (2016) Population structure of edible dormouse in Poland: the role of habitat fragmentation and implications for conservation. J Zool 298(3):217-224

Hubisz MJ, Falush D, Stephens M, Pritchard JK (2009) Inferring weak population structure with the assistance of sample group information. Mol Ecol Resour 9:1322-1332

Hürner H, Martin JF, Ibas AR, Arrizabalaga A, Michaux JR (2009) Isolation, characterization and PCR multiplexing of polymorphic microsatellite markers in the edible dormouse Glis glis. Mol Ecol Resour 9:885-887

Hürner H, Kryštufek B, Sarà M, Ribas A, Ruch T, Sommer R, Ivashkina V, Michaux JR (2010) Mitochondrial phylogeography of the edible 
dormouse (Glis glis) in the western Palearctic region. J Mammal 91: 233-242

Jurczyszyn M (1996) New localities of the fat dormouse Myoxus glis in Szczecińskie Province. Chroń Przyr Ojcz 52:106-111

Jurczyszyn M (2001) Reintroduction of the edible dormouse (Glis glis) in Sierakowski Landscape Park (Poland), preliminary results. Trak Univ J Scient Res B 2:111-114

Jurczyszyn M (2015) Atlas ssaków Polski. Instytut Ochrony Przyrody PAN, (www.iop.krakow.pl/ssaki/Katalog.aspx)

Jurczyszyn M, Wołk K (1998) The present status of dormice (Rodentia, Myoxidae) in Poland. Nat Croat 7:11-18

Kalinowski ST, Taper ML (2006) Maximum likelihood estimation of the frequency of null alleles at microsatellite loci. Conserv Genet 7:991-995

Lanfear R, Calcott B, Ho SYW, Guindon S (2012) Partition finder: combined selection of partitioning schemes and substitution models for phylogenetic analyses. Mol Biol Evol. doi:10.1093/molbev/mss020

Lo Brutto S, Sara M, Aeculeo M (2011) Italian Penisula preserves an evolutionary lineage of the fat dormouse Glis glis L. (Rodentia: Gliridae). Biol J Linn Soc 102:11-21

Michaux JR, Magnanou E, Paradis E, Nieberding C, Libois R (2003) Mitochondrial phylogeography of the wood-mouse (Apodemus sylvaticus) in the western Palearctic region. Mol Ecol 12:685-697

Mikusek R (2010) Góry Stołowe. Natura 2000 na Dolnym Śląsku i Opolszczyźnie kompendium internetowe (www.natura2000dolnyslask.pl)

Pilastro A, Tavecchia G, Marin G (2003) Long living and reproduction skipping in the fat dormouse. Ecology 84:1784-1792

Piry S, Luikart G, Cornuet J-M (1999) BOTTLENECK: a computer program pro detecting recent reductions in the effective population size using allele frequency data. J Hered 90(4):502-503

Pritchard JK, Stephens M, Donnelly P (2000) Inference of population structure using multilocus genotype data. Genetics 155:945-959
Pucek Z (1983) Glis glis (Linnaeus, 1766). In: Pucek Z and Raczyński J (eds) Atlas rozmieszczenia ssaków w Polsce, PWN, Warszawa, pp $135-136(+127)$

Pucek Z, Jurczyszyn M (2001) Glis glis (Linnaeus, 1766). In: Głowaciński Z (ed) Polish red book of animals. Państwowe Wydawnictwo Rolnicze i Leśne, Warszawa, pp 79-81

Rodriguez R, Ramirez O, Valdiosera CE, García N, Alda F, MadurellMalapeira J, Marmi J, Doadrio I, Willerslev E, Götherström A, Arsuaga JL, Thomas MG, Lalueza-Fox C, Dalén L (2011) 50,000 years of genetic uniformity in the critically endangered Iberian lynx. Mol Ecol 20(18):3785-3795

Ronquist F, Teslenko M, van der Mark P, Ayres DL, Darling A, Höhna S, Larget B, Liu L, Suchard MA, Huelsenbeck JP (2012) MrBayes 3.2: efficient Bayesian phylogenetic inference and model choice across a large model space. Syst Biol 61:539-542

Rousset F (2008) Genepop'007: a complete reimplementation of the Genepop software for Windows and Linux. Mol Ecol Resour 8: 103-106

Segelbacher G, Tomiuk J, Heinz T, Kuhn J, Weis-Dootz T, Fietz J (2010) Isolation of di- and tetranucleotide microsatellite loci in the edible dormouse (Glis glis). In: Aurelle D, Baker AJ, Bottin L et al (eds) Molecular ecology resources primer development consortium, vol 10, Mol Ecol Resour., pp 751-754

Staffa M (1992) Góry Stołowe. Słownik geografii turystycznej Sudetów. Wydawnictwo PTTK "Kraj” t.13

Taylor AC, Walker FM, Goldingay RL, Ball T, van der Ree R (2011) Degree of landscape fragmentation influences genetic isolation among populations of a gliding mammal. PLoS ONE 6(10):e26551

Trzop K, Moska M (2013) Dormice (Gliridae) of Ślęża landscape park. Chroń Przyr Ojcz 69:409-414

Van Oosterhout C, Hutchinson WF, Wills DPM, Shipley P (2004) Microchecker: software for identifying and correcting genotyping errors in microsatellite data. Mol Ecol Notes 4:535-538

Zwickl DJ (2006) Genetic algorithm approaches for the phylogenetic analysis of large biological sequence datasets. Philosophy 115 . 